\title{
Monitoração ambiental no setor de biotecnologia: comportamento de busca e uso de informação em empresas de micro e pequeno portes de Minas Gerais
}

\author{
Environmental scanning in the biotechnology sector: behavior of \\ search and use of information in small and medium-size companies \\ of Minas Gerais
}

Adriana Duarte NADAES

Mônica Erichsen Nassif BO RGES²

RESUMO

Este artigo relata os resultados de uma pesquisa de Mestrado da Escola de Ciência da Informação da UFM G que teve como objetivo investigar o comportamento de busca e uso de informação sobre o ambiente organizacional externo, por parte dos gesto res das empresas de micro e pequeno portes do segmento de biotecnologia de Belo Horizonte/Minas G erais. Com esta pesquisa procurou-se responder às seguintes questões: se é fato que as organizações devem interagir com o ambiente externo para desenvolver e manter sua competitividade, qual é a importância do processo de busca e uso de informações externas? Sob que condições o uso das informações coletadas to rna-se um redutor de incertezas para as organizações de micro e pequeno portes? Esta pesquisa foi desenvolvida utilizando-se da análise qualitativa, obtida com a realização de entrevistas com gestores de empresas de biotecnologia mais especificamente ligadas ao segmento de saúde humana da área de diagnóstico, na região de Belo Horizonte, Minas $\mathrm{G}$ erais. 0 s resultados levam-nos a concluir que ambientes, cenários e pessoas diferentes têm necessidades, comportamentos, análises e usos de informações diferenciados. $N$ ão existe um padrão único de comportamento de busca e uso de informações externas, e a redução das incertezas independe da quantidade de informação coletada e ou mesmo processos estruturados. A redução da incerteza se concentra nos indivíduos e na sua capacidade pessoal de adicionar valor à "informação", informação esta que poderá ser utilizada para responder a uma pergunta, resolver um problema, to mar uma decisão, negociar uma posição ou compreender uma situação.

Palavras-chave: monitoração ambiental; busca e uso da informação; micro e pequena empresa e biotecnologia.

1 Mestre em Ciência da Informação, especialista em Gestão Estratégica da Informação pela Escola de Ciência da Informação da Universidade Federal de Minas Gerais e especialista em Comunicação Empresarial pelo Instituto de Educação Continuada da Pontifícia Universidade Católica de Minas G erais. Coordenadora do Curso de Comunicação Social e Docente da Faculdade Brasileira de Ciências Exatas, Humanas e Sociais - FABRAI e docente do Departamento de Comunicação Social, Pontifícia Universidade Católica - PUC MINAS ARCOS. Belo Horizonte, MG, Brasil. Corresponde para/Correspondence to: A.D. NADAES. Email: <adriananadaes@ terra.com.br>.

2 Doutora em Ciência da Informação. Docente, Escola de Ciência da Informação, Universidade Federal de Minas Gerais. Av. Antônio Carlos, 6627, Bairro Pampulha, 30161-970, Belo Horizonte, MG, Brasil. E-mail: <mnassif@ eci.ufmg.br>. Recebido em 7/5/2007 e aceito para publicação em 31/7/2007. 


\section{ABSTRACT}

This article tells the results of a research of M estrado of the School of Science of the Information of the UFM G that had as objective to investigate how the managers of small and medium-size biotechnology companies, in Belo Horizonte/M inas G erais, search and use the information concerning the companies external environment. It answers the following research questions: assuming that organizations must interact with the external environment to develop and keep its competitiveness, what is the real importance of the process of search and use of external information? Under which conditions the use of the information gathered can reduce uncertainties for small and medium-size companies? This research uses qualitative analysis based on personal interviews with some managers of biotechnology companies, especifically those companies working in the field of human health diagnosis, located in the Belo Horizonte region. The results show that different environments, scenarios and people have different needs, behaviors and different analysis and uses of information. There is no standard behaviour on the search and use of external information. The reduction of uncertainties is neither dependent on the quantity of information gathered nor on the structured processes. The reduction of uncertainty is centered on the individuals and on their personal capacity to add value to the piece of information. This piece of information can be used to answer a question, to solve a problem, to make a decision, to negotiate a position or to comprehend a situation.

Keywords: evironmental scanning; information use and search; small and medium-size companie and biotechnology.

\section{INTRO DUÇÃO}

A aceleração do progresso econômico nos setores mais desenvolvidos da humanidade, que ocorre, em grande parte, como decorrência direta do advento das tecnologias da informação e comunicação (TICS), vem ocasionando contínuas e profundas transformações nas organizações, nos seus métodos de trabalho, na pesquisa, produção e utilização das informações de que necessitam. A complexidade das mudanças enseja ameaças de desaparecimento precoce para muitas organizações não adaptadas aos novos tempos, mas, também, sobretudo, as brinda com novas oportunidades de expansão na dimensão de seus negócios.

E os gesto res das organizações mo dernas têm sofrido com esta crescente avalanche de informações geradas pelo atual ambiente de negócios. Esforços vêm sendo realizados com o intuito de auxiliar na tarefa de filtrar e identificar informações importantes aos negócios, no entanto, levantar as necessidades informacionais não é tarefa fácil, pois lidamos com pessoas, e, seus diferentes comportamentos cognitivos, frente à informação e o uso da mesma como fator de vantagem competitiva.

A informação e o seu correto monitoramento passaram a ser vistos como recursos fundamentais dentro das organizações e a gestão estratégica destes recursos, por sua vez, passou a depender fundamentalmente do uso inteligente da tecnologia adequada. Começou-se, então, a perceber a necessidade do desenvolvimento de modelos, métodos e softwares que satisfizessem e se adequassem ao novo cenário. Entretanto, os recursos tecnológicos, por si só, não satisfazem boa parte das necessidades de informação, busca e uso destas no âmbito das organizações modernas, que precisam cada vez de informações subjetivas como insumo do trabalho, objetivando transformar dados e informações em conhecimento estratégico.

Porter (1997) observa que as organizações possuem uma enorme necessidade de dados sobre a concorrência e o ambiente, pois a informação se constitui como insumo básico da idealização dos modelos competitivos, os quais são à base da formulação estratégica competitiva.

Davenport (1998) já dizia que o mercado mundial de informação, de maneira geral, é vasto e cresce a um ritmo acelerado. Em 1998 já existiam mais de dois mil bancos de dados on-line, sem contar as inúmeras organizações que produzem e vendem informações em formatos não autorizados e as milhões de fontes de informações da Web.

Este cenário caracteriza-se por apresentar um grau de incerteza cada vez mais elevado, que reflete uma crescente hostilidade ambiental, acirra a competição e provoca profundas mudanças na conduta administrativa.

Desta forma, é preciso perceber que informações sobre tendências, objetivos, posicionamento e movimentação de concorrentes e clientes carregam em 
si um valor inestimável ao planejamento estratégico de uma organização, assim como outras informações de caráter externo, como as de âmbitos econômico, tecnológico, as regulatórias, as sócio-culturais. E é a capacidade de interagir com a ambiente externo de forma pró-ativa que deve fazer parte da postura organizacional, o que levará as organizações à criação de seus diferenciais frente à concorrência, que se acirra cada vez mais neste novo cenário mundial. Assim, entendemos que esta pesquisa está relacionada não somente à monitoração do ambiente externo, mas, também, aos indivíduos/sujeitos (gestores).

Dentro desta perspectiva, alguns questionamentos se fazem relevantes. Se é fato que as organizações devem interagir com 0 ambiente externo para desenvolver e manter sua competitividade, qual é a importância do processo de busca e uso de informações externas? Sob que condições o uso das informações coletadas torna-se de fato um redutor de incertezas para as organizações de micro e pequeno portes?

Com vistas e encontrar respostas a essas perguntas, o objetivo geral deste trabalho foi o de investigar o comportamento de busca e uso da informação sobre o ambiente organizacional externo por parte dos gestores de empresas de micro e pequeno portes do setor de biotecnologia, e os objetivos específicos foram: identificar o perfil dos gestores pesquisados, no que tange à experiência destes na área e as atividades que exercem dentro da organização; analisar qual a importância do processo de busca e uso de informações externas para os gestores das organizações de micro e pequeno portes e verificar em que condições o uso das informações coletadas torna-se de fato um redutor de incertezas para os gestores das organizações de micro e pequeno portes.

\section{REFEREN CIAL TEÓ RICO : MO N ITO RAÇÃO AMBIENTAL}

Um dos primeiros pesquisadores a estudar 0 ambiente como uma fonte de informação foi Dill (1962 apud Choo, 1998a). Ele sugeriu que a melhor maneira de analisar o ambiente não é tentando entendê-lo como um conjunto de sistemas ou organizações, mas vendoo como informação que se torna disponível para a organização, por meio de uma atividade de busca.
As mudanças, os eventos, as ameaças e as oportunidades no ambiente continuamente criam sinais e mensagens. As organizações detectam ou recebem essas sugestões e usam a informação para se adaptarem às novas condições.

De acordo Choo (1998c, p.123)

$N$ ão é fácil perceber mensagens potencialmente importantes no ambiente, porque a organização mergulha em múltiplas correntes de interação com muitas diferentes partes do ambiente, e porque quase todas as partes do ambiente interligam-se com outras partes de maneiras complexas e imprevisíveis.

Assim, tipicamente, obter recursos significa que a organização deve interagir com as entidades que as controlam. N esse sentido, as organizações dependem de seus ambientes e a sobrevivência é parcialmente explicada pela habilidade em enfrentar as contingências ambientais.

Nos últimos anos, as surpresas de ordem estratégica para um número cada vez maior de organizações materializam-se dentro de pequenos espaços de tempo.

M cgee \& Prusak (1994) destacam que o avanço tecnológico não conseguiu solucionar o principal problema das empresas: definir a informação correta, em tempo hábil, e no local adequado. Definir o que se precisa, como, onde e quando ainda é tarefa humana, e cabe aos indivíduos, gestores das organizações, enquanto seres cognoscentes, estabelecerem suas necessidades e a partir delas definir mecanismos de coleta, análise e disseminação da informação, de forma a transformá-la em vantagem competitiva.

De acordo com Sapiro (1993), para o qual, sem que os dados obtidos se transformem em informação e que sejam realmente utilizadas, as empresas falharão na busca da obtenção da vantagem competitiva. De forma a se obter sucesso em uma estratégia para a implantação de uma função de monitoramento e obtenção de informações que contribua para a melhoria dos processos como um todo, devemos levar sempre em conta a realidade enfrentada por cada organização, seu contexto sócio-econômico, político e cultural e as pessoas que dela participam, e que são fundamentais. 
NECESSIDADES, CO MPO RTAMENTO DE BUSCA E USO DA INFO RMAÇÃO

De acordo com Choo (2003), os estudos sobre necessidades e usos da informação contribuíram significativamente para que possamos entender como as pessoas buscam a informação. Porém embora os estudos continuem a proliferar, há uma crescente intranqüilidade pelo fato de não estar ocorrendo a construção de um conhecimento teórico unificador sobre as necessidades e usos da informação. Várias são as frentes de trabalho sem diálogo, o que reforça a necessidade de estudos interdisciplinares.

Choo (2003) mostra-se consciente de que uma generalização é difícil, porque muitos estudos limitaramse a grupos de usuários com demandas especiais de informação e à sua interação com instrumentos, canais de sistemas de informação específicos, fundamentalmente por uma falta de consenso sobre a definição de conceitos como necessidade e informação, uso da informação e outras variáveis importantes.

Segundo Rouse e Rouse (1984, p.129), "o ser humano raramente busca informação como um fim em si mesma". Choo (2000) afirma ainda que o planejamento e a tomada de decisões são os principais geradores de necessidades cognitivas de informação. 0 autor ainda cita Wilson (1981), para quem a informação tem que satisfazer não só as necessidades cognitivas, mas, também, as necessidades afetivas, assim como as necessidades situacionais.

Choo (2003), em estudos mais recentes descreve que, conceitualmente, a busca da informação ocorre em três estágios: o reconhecimento das necessidades de informação, que leva à busca e, depois, ao uso da informação. De acordo com esse autor "na prática, esses estágios tendem a desdobrar-se e entrelaçar-se, de modo que cada atividade é um microcosmo para uma ou mais das outras atividades “ (p.99).

De acordo com Choo (2003), "a busca da informação é o processo pelo qual o indivíduo engajase decididamente em busca de informações capazes de mudar seu estado de conhecimento" (p.102). Assim, a busca de informações faz parte de uma atividade social por meio da qual a informação torna-se útil para um indivíduo ou para um grupo. Já o seu uso é um conceito de difícil definição satisfatória. Entretanto, para desenvolver seu modelo, Choo (2003), considerou o uso da informação pragmaticamente: "o indivíduo seleciona mensagens entre um grupo maior de mensagens que recebe ou acompanha. Ele faza escolha quando percebe uma relação significativa entre 0 conteúdo da mensagem e a tarefa ou problema que tem em mãos" (p.107). Assim, o resultado do uso da informação será uma mudança no estado de conhecimento do indivíduo ou de sua capacidade de agir. Portanto, de acordo com o autor, podemos considerar que o uso da informação envolve a seleção e o processamento da informação, de modo a responder a uma pergunta, resolver um problema, tomar uma decisão, negociar uma posição ou entender uma situação.

Depois de anos em que se condenou a falta de uma estrutura teórica, de acordo com Choo (2003, p.83), caminha-se para um consenso sobre o que, em uma análise dos usos e necessidades da informação, constitui os seus elementos definidores. Consciente de que o estudo das necessidades e usos da informação é necessariamente um estudo transdisciplinar, ligando áreas como a psicologia cognitiva, estudos de comunicação, difusão de inovações, economia, teoria organizacional e antropologia social, o autor afirma, que ao mesmo tempo, essa diversidade pressiona por uma perspectiva unificadora que dê coerência ao grande volume de pesquisas sobre a busca e o uso da informação.

Um modelo de uso da informação deve englobar a totalidade da experiência humana: os pensamentos, sentimentos, ações e o ambiente onde eles se manifestam. Partimos da posição de que o usuário da informação é uma pessoa cognitiva e perceptiva; de que a busca e o uso da informação constituem um processo dinâmico que se estende no tempo e no espaço; e de que o contexto em que a informação é usada determina de que maneiras e em que medida ela é útil.

Para a construção de modelos de busca e uso de informações, Choo (2003) baseou-se em diversos autores, embora tendo sempre como referências as necessidades cognitivas, as reações emocionais e as dimensões situacionais. 


\section{Modelo de busca de informação}

0 modelo de Choo (2000) define busca de informação como um processo pelo qual propositadamente se procura por mensagens, documentos, dados etc. pela identificação, seleção e intera ção com fontes. Ele analisa o comportamento de busca de informação a partir de três dimensões, quais sejam: a cognitiva, a afetiva e a situacional.

De acordo com Choo (2000), na dimensão cognitiva são estabelecidos critérios para a seleção da informação, como utilidade, precisão, relevância e confiabilidade, sendo que os dois últimos (relevância e confiabilidade) foram adotados neste artigo como sendo os atributos utilizados para a avaliação da qualidade da fonte de informação. Q ualidade da informação que pode ser vista como adequação a padrões estabelecidos pela necessidade do consumidor da informação.

Segundo Paim, Nehmy e G uimarães (1996), qualidade da informação, engloba uma miríade de atributos diversos e variáveis como validade, confiabilidade, precisão, completeza. De acordo com sua percepção, o indivíduo selecionará a fonte que possui a maior probabilidade de conter a info rmação relevante e útil, levando-se em consideração a relação custo x benefício.

Ao analisarmos o modelo de Choo (2000), podemos dizer que, segundo 0 autor, a dimensão cognitiva é analisada do ponto de vista das características da informação por Zmud (1978), Saracevic (1975) e por Eisenberg e Schamber (1998). 0 primeiro identifica as seguintes características: quantidade (completa ou suficiente); confiabilidade (verdadeira; acurada); oportunidade e qualidade do formato. 0 segundo autor centra-se no conceito de relevância. Segundo Eisenberg e Schamber (1998), este é definido como indicador de importância, dada pela relação entre o objeto julgado e uma estrutura de referência que 0 indivíduo já possui. $0 \mathrm{~s}$ dois outros autores definem a relevância a partir da medida de utilidade entre um documento e uma questão julgada pelo sujeito. A relevância depende do julgamento humano, de sua percepção e conhecimento, e não de características inerentes ao documento ou à informação.

Q uanto à dimensão afetiva, Choo (2000) referese ao grau de motivação e interesse pessoal pelo problema ou tópico que determina a soma de energia gasta na busca de informação.

N essa perspectiva, Kuhlthau (1993) sugere que a procura é um processo de construção de entendimento e de sentido. Apresenta como eixo a formulação de um foco, idéia guia ou ponto de vista. Desta forma, o resultado na busca de informações é influenciado pelo humor e pelas atitudes do sujeito em face à tarefa de busca. Esta se constitui, portanto, em uma série de escolhas únicas e pessoais, baseadas nas expectativas do usuário, sobre que fontes de informação e estratégias serão efetivas ou oportunas na solução dos problemas apresentados.

Kuhlthau (1993) postula que a busca de informação é composta de seis estágios, quais sejam: iniciação, seleção, exploração, formulação, coleção e apresentação. No decorrer da busca, caso se obtenha sucesso, crescem os níveis de interesse e motivação do usuário, e os sentimentos variam de incerteza a satisfação.

Já no nível situacional Choo (2000), acredita que a busca da informação será a soma de tempo e esforço requerida para localizar e contatar a fonte e interagir com ela de modo a extrair a informação que influencia sua seleção e uso. Muitos estudos destacam que a acessibilidade da fonte é fator predominante em sua escolha. Gerstberger e Allen (1968) definem acessibilidade como 0 grau pelo qual se pode obter contato significativo com o canal de informação. Para Culnan (1985), corresponde ao nível esperado de esforço requerido para usar uma fonte de informação particular.

Em suma, de acordo com o modelo de Choo (2000) podemos concluir que o processo de busca de informação pode ser considerado como sendo influenciado por fatores cognitivos, afetivos e situacionais, sendo que as variações nessas dimensões é que irão certamente configurar distintos comportamentos de busca de informação.

N esse artigo é reconhecida a existência de um amplo conjunto de estudos que procuram identificar 0 processo de busca de informações em diversas áreas de conhecimento. Porém não há neste estudo, a intenção de se identificar e citar todos eles, a penas de fornecer um quadro referencial que pudesse auxiliar e conciliar a análise dos dados pesquisados, sob um mesmo prisma e olhar. 


\section{Modelo de uso de informação}

0 modelo de uso de informação apresentado por C hoo (2003), se divide em três categorias, a saber:

(1) Meio social ou profissional - as características do meio e/ou do ambiente de uso da informação do indivíduo podem induzir ou restringir certos comportamentos de busca da informação. Sendo que a cultura e a estrutura da organização ou do grupo de trabalho afetam as atitudes do indivíduo em relação à coleta de informação. Assim, o início, ou identificação das fontes, pode ser restringido pelo grau de acesso às fontes de informação e pelo fluxo de informação dentro da organização. 0 monitoramento e a extração variam de acordo com as exigências da tarefa ou com o campo em que ela será realizada.

(2) Necessidades cognitivas - Dervin (1992) vê a busca da informação como uma tentativa de preencher os vazios do conhecimento. A maneira com que as pessoas percebem e definem seus vazios cognitivos é um bom indício de como elas tentam superá-los, ou seja, como buscam informação para satisfazer suas necessidades.

(3) Reações emocionais - Kuhlthau (1993) descreve como a incerteza surge e decresce no curso da busca da informação, e como a ansiedade inicial pode ser substituída por uma confiança crescente à medida que a busca prossegue. Sendo que o estado de espírito com que o indivíduo empreende a pesquisa também pode influenciar a extensão e profundidade da busca. 0 indivíduo também pode ser afetado pela quantidade e originalidade da informação encontrada, o que pode lhe gerar estados de alívio, satisfação e/ou mesmo decepção.

0 uso da informação éo estágio final do modelo, nele 0 indivíduo atua sobre a informação selecionada para, por exemplo, responder a uma questão, solucionar um problema, tomar uma decisão, negociar uma posição ou dar sentido a uma situação. 0 resultado do uso da informação é, portanto, uma mudança no estado de conhecimento do indivíduo. Sendo este um processo contínuo e recorrente durante todo o processo de busca.

0 modelo apresentado por Choo (2003), é uma tentativa de identificar e relacionar os principais elementos que influenciam o comportamento do indivíduo quando busca e usa a informação.

\section{METO DO LO G IA}

Assim, como o objetivo geral do presente trabalho foi 0 de investigar o processo pelo qual os gestores das empresas de micro e pequeno portes, do setor de biotecnologia lidam com informações oriundas do ambiente externo de suas organizações, optamos pelo método qualitativo, que segue a tradição compreensiva ou interpretativa das ações humanas, partindo do pressuposto de que as pessoas agem em função de aspectos como: hábito, atitudes, valores, percepções, crenças, tendências de comportamento, etc.

Entendendo que a definição dos instrumentos de coleta de dados depende dos objetivos almejados com a pesquisa e do universo a ser pesquisado, a coleta de dados desta pesquisa foi feita mediante entrevistas presenciais aplicadas no universo de empresas pesquisadas a um de seus principais executivos (gestores), como forma de interação entre o pesquisador e o objeto de pesquisa. As entrevistas se basearam num roteiro pré-definido, originado da revisão bibliográfica.

A entrevista foi respondida pelos gestores previamente selecionados das micro e pequenas empresas do setor de biotecnologia.

0 roteiro de entrevista considerou alguns dos aspectos abordados na revisão de literatura. 0 roteiro de entrevista foi estruturado em quatro blocos. 0 primeiro bloco conteve perguntas acerca dos dados da empresa do respondente, descrição da organização de forma suscinta e do sentimento que este têm em relação mercado ao qual sua organização está inserida, o segundo bloco constituiu-se de perguntas pessoais, visando principalmente entender o contexto no qual está inserido. No terceiro bloco, procuramos analisar 0 ambiente no qual o respondente está inserido, bem como, analisar seu comportamento de busca e uso de informações. No quarto e último bloco, é utilizada a técnica de incidente crítico, tendo como objetivo fazer com que 0 entrevistado descrevesse uma situação extremamente relevante para a organização enfrentada nos últimos 2 anos e a forma como o mesmo procedeu para buscar uma possível solução.

Após realização do pré-teste para validação do instrumento de coleta de dados, bem como, para avaliação do tempo gasto com a entrevista, 
selecionamos nosso universo de amostra. Como o préteste foi realizado com uma empresa de grande representação no segmento, a Biominas e, tendo em vista que a pessoa entrevistada compõe o quadro estratégico da Empresa, decidimos por também aproveitar o seu resultado.

Das 19 empresas registradas que compõem 0 quadro de micro e pequenas empresas (MPEs) do setor de biotecnologia, decidimos por focar nosso estudo em um único segmento, que foi o de saúde humana na área de diagnóstico. Das 19 empresas de biotecnologia, somente 9 correspondiam a este perfil.

Destas, somente 5 gestores das MPEs instaladas em Minas Gerais, Região Metropolitana de Belo Horizonte foram entrevistados, pois 2 se recusaram participar alegando indisponibilidade de tempo e 2 após insistentes telefonemas e envio de e-mails alegaram que suas empresas não possuíam o perfil adequado para este tipo de trabalho e não gostariam de expor informações, de acordo com eles estritamente confidenciais. Dessa forma, conseguimos obter um resultado bastante satisfatório com um total de 6 empresas pesquisadas, sendo: 1 - Biominas, caso tratado a parte e, 3 empresas eram de micro porte e 3 empresas de pequeno porte, escolhidas a partir de três critérios:

(1) o universo pesquisado se restringiu às empresas de micro e pequeno portes, sendo que, das 19 existentes em Belo Horizonte, foram definidas para desenvolvimento da dissertação, apenas 9: as que compõem o segmento de saúde humana na área de diagnóstico;
(2) a incorporação da Fundação Biominas, como amostra aceitável, e;

(3) 0 foco do estudo concentrou-se nos gestores das organizações selecionadas.

A fim de validarmos nossa amostra e quadro atual das empresas selecionadas na amostra, criamos a tabela 1 , que se apresenta a seguir.

\section{AN ÁLISE DAS EN TREVISTAS}

Para proceder à análise das entrevistas, utilizamos como parâmetros três categorias de análise que perpassam pela revisão de literatura, metodologia e pelo instrumento de coleta de dados, quais sejam: 0 ambiente organizacional, o perfil dos gestores e 0 comportamento de busca e uso da informação.

\section{Primeira categoria de análise - O AMBIENTE} O RGANIZACIO NAL

Em relação ao tempo de existência das empresas pesquisadas, observamos uma distribuição bem diversificada. Em se tratando de empresas de micro e pequeno portes, o tempo de existência das empresas pesquisadas é um dado relevante, tendo em vista que, de acordo com o Boletim Estatístico de Micro e Pequenas Empresas, realizado pelo Sebrae (2005), que demonstrou que o índice de mortalidade das MPEs é razoavelmente elevado. De acordo com o resultado apontado $49,9 \%$ das empresas encerram as atividades com até 2 anos de existência; $56,4 \%$ com até 3 anos; e, 59,9\% com até 4 anos.

Tabela 1. Área de diagnóstico: quadro de constituição, tempo de existência e número de acionistas do segmento de biotecnologia.

\begin{tabular}{l|c|c|c|c}
\hline & Constituição & No Sócios/Acionistas & Tempo de existência/anos & Enquadramento das empresas \\
\hline Empresa 1 & Mista & 7 & 16 & Micro empresa \\
\hline Empresa 2 & Familiar & 4 & 8 & M icro empresa \\
\hline Empresa 3 & Mista & 10 & 2 & Pequena empresa \\
\hline Empresa 4 & Mista & 4 & 6 & Pequena empresa \\
\hline Empresa 5 & Familiar & 2 & 29 & Pequena empresa \\
\hline Empresa 6 & Mista & 2 & 7 & Micro empresa \\
\hline
\end{tabular}

Fonte: Elaborado pela autora - pesquisa 2006. 
Ao analisarmos, com os gestores entrevista dos, o mercado em que suas empresas atuam, a grande maioria foi unânime em afirmar que se trata de um mercado altamente competitivo, o que demanda das organizações a necessidade de se considerar uma gama mais ampla de informação estratégica do que aquela existente na maioria das organizações, o que reforça o modelo de Porter (1997) - As cinco forças competitivas que determinam a rentabilidade da indústria.

0 utro ponto importante que cabe destacar é que, apesar dos estudos realizados pela no Instituto Mckinsey (1999), que aponta a existência de um "embrião de cluster" ou arranjos produtivos locais em biotecnologia na região de Belo Horizonte, os gestores através das entrevistas realizadas apontam para uma não consolidação do conceito e da prática real aplicada no segmento.

De acordo com alguns depoimentos o segmento de biotecnologia é visto muito mais sob o prisma da competição do que do ponto de vista do somar competências. E o impacto deste olhar recai sobre a não existência de fluxos informacionais, estruturados ou não, impactando na não existência consolidada da prática de um embrião de cluster.

Em contra-partida, observamos que o sucesso deste pólo tem como base não apenas a competência empresarial no investimento em pesquisas e produção científica, o estoque de conhecimentos gerados na Universidade Federal de Minas G erais - UFMG - e em outras instituições universitárias; como também 0 alto investimento das organizações pesquisadas em desenvolver competências científicas e de $P \& D, 0$ que pôde ser comprovado por alguns dos depoimentos prestados.

Também nos foi possível constatar que, se não todos, a maioria dos entrevistados entendem a importância de se trabalhar de forma estratégica e direcionada, conhecem bem o seu ambiente externo de negócios do ponto de vista da concorrência, entrantes potenciais, fornecedores, compradores e substitutos. Estes comungam da teoria de Mcgee e Prusak (1994), que diz que a estratégia competitiva implícita ou explicitamente (cuidadosamente definida ou existente de maneira informal) é manifestada em processos organizacionais específicos que transformam vários recursos (capital, tecnologia, trabalho, matériasprimas, etc.) em produtos e serviços que fornecem valor aos clientes. Todos os entrevistados demonstraram estar satisfeitos com a estabilidade de seus negócios e das vendas dos seus produtos, a pesar de reconhecerem as dificuldades do seu ramo de negócios e a necessidade de toda empresa em investir em inovação, seja de produto ou de processo produtivo.

Constatamos também que, das empresas pesquisadas, somente aquelas que são consideradas como pequenas empresas possuem um setor específico para coleta, organização e distribuição de informações sobre 0 ambiente organizacional externo. M esmo assim o setor específico para tal fim é o setor de marketing, setor este não estruturado somente para tal objetivo, mas que exerce a função de também coletar, processar, analisar e disseminar informações estratégicas ao negócio da empresa, ainda que de forma embrionária e não sistematizada.

Entretanto, três aspectos devem ser ressaltados. 0 primeiro diz respeito à EM PRESA 3, que, após uma fatalidade que levou a uma perda significativa de investimento, percebeu a necessidade de se criar um setor estruturado, embora ainda embrionário.

0 segundo fica por conta da EM PRESA 5, que é a empresa que possui maior tempo no mercado, sendo assim a mais estruturada e organizada, tanto do ponto de vista organizacional, bem como do ponto de vista informacional.

0 terceiro fica por conta das micro empresas que, pelo seu porte não se encontram aptas a possuir um setor informacional organizado. N estas a coleta, a organização e a disseminação da informação ficam por conta dos seus próprios gestores.

Com relação aos desafios mais enfrentados neste mercado, foi-nos possível constatar que se trata de um segmento com alto nível de incerteza, muito novo, porém altamente inovador.

Ao analisarmos o processo de coleta de informações em função dos desafios apresentados, constatamos que a maioria dos entrevistados se vêem compelidos à busca de informações do ambiente externo de negócios em função dos desafios hoje enfrentados por estes.

Ao analisarmos os problemas mais enfrentados pelos entrevistados, constatamos que os mesmos se diferem, de acordo com contextos e com as pessoas envolvidas. 
Taylor (1986), considera que, embora uma situação problemática seja criada e definida por um indivíduo único, ela é também modelada por traços do ambiente, que variam de organização para organização, dadas as suas próprias características.

0 resultado apresentado nos leva a concordar com Choo (1998a), quando o autor aponta que a necessidade de informação surge de problemas, incertezas e ambigüidades encontradas em experiências e situações específicas de uma organização. Sendo que cada situação e cada experiência é composta de um grande número de fatores que se relacionam não somente ao assunto em questão como, também, a fatores contextuais como o estilo organizacional, as restrições funcionais, o consenso e a definição clara de objetivos, grau de risco e normas profissionais.

Foi-nos possível detectar também que, para uma boa parte dos entrevistados, o termo monitoração do ambiente externo de negócios é freqüentemente utilizado, principalmente pelas organizações com 0 maior tempo de existência, e que possuem um setor específico para tal, em algumas delas através da área de marketing. Porém, ao compararmos a prática aplicada com a literatura da área, podemos avaliar que, apesar de grande parte dos entrevistados afirmarem ser freqüente 0 uso e a aplicabilidade do termo "monitoração do a mbiente", estes não o fazem em sua to talidade. Segundo Choo (1998a) "monito ração de ambientes organizacionais é a aquisição e uso da informação sobre eventos, tendências e relações em seu ambiente externo, cujo conhecimento auxiliará os gerentes a planejar as futuras ações."

$\mathrm{E}$, de acordo com os depoimentos prestados, observamos não ser uma prática usual a coleta de informações que visem um escopo tão amplo, mas, sim, muito mais uma prática de "Inteligência Competitiva", que, de acordo com Choo (1998c), constitui como sendo a "atividade de monitoração do ambiente externo por informações consideradas relevantes para o processo de tomada de decisões nas organizações (p.74)."

Segundo Porter (1997), a essência da formulação da estratégia competitiva encontra-se na ação de relacionar uma organização ao seu meio ambiente. Sob esta ótica, entende-se que a organização precisa perceber claramente a maneira como interage no mercado, assim como reconhecer as ameaças e oportunidades que se apresentam, para que possa planejar sua estratégia e linhas de ação.

Segunda categoria de análise - O PERFIL DOS GESTO RES

Foi-nos possível, a partir dos dados obtidos através das entrevistas, observar que as empresas familiares e seus gestores foram os que responderam sobre o meio de negócios no qual suas empresas estão inseridas com uma visão mais ampliada sobre as suas possibilidades de atuação, sobre a amplitude da concorrência, so bre suas potencialidades. Além disso, foram os que mostraram ter uma preocupação maior com a informação e os que demonstraram maior disponibilidade de tempo e interesse para a efetividade da entrevista.

Com relação às atividades que exercem dentro das organizações, as respostas são variadas. Diferemse de acordo com o cargo e com a função que cada um ocupa na organização. Apesar de todos os entrevistados serem sócios proprietários e principais gestores das empresas pesquisadas, seus cargos e funções são diferentes, de organização para organização.

Terceira categoria de análise - COMPO RTAMENTO DE BUSCA E USO DA INFO RMAÇÃO

Ao analisarmos, nas atividades diárias dos entrevistados, o que lhes consome mais tempo, foi-nos possivel constatar que para a grande maioria é a busca de informações. Informações, em sua maioria, ligadas às suas funções específicas e ao foco do negócio.

Um ponto significativo que está relacionado ao modo de monitoração de ambientes organizacionais é que, apesar de a grande maioria dos gestores entrevistados ter afirmado que monitora o ambiente externo sistematicamente, esta busca se faz inicialmente pela exposição direcionada. De acordo com Aguilar (1967), há quatro modos de busca de informação: exposição não direcionada e direcionada, busca formal e informal. 
Mediante as respostas apresentadas podemos concluir que os gestores entrevistados se utilizam do modo de monitoração da exposição direcionada, o que de acordo com Aguilar (1967), significa: na exposição direcionada, 0 indivíduo focaliza o seu interesse sobre tópicos selecionados ou sobre certos tipos de informação. 0 objetivo é avaliar o significado da informação encontrada para que se possa dimensionar a natureza geral do impacto na organização. Este dimensionamento é realizado sob uma perspectiva de custo-benefício, sem ter de dedicar esforço e tempo substanciais à procura formal. Se o impacto for suficientemente significante, o modo de monitoração muda de exposição para busca.

A grande dificuldade de acordo com Aguilar (1967), e suas palavras são respaldadas pelos depoimentos dos entrevistados, é determinar quais são as informações relevantes e disponíveis para cada necessidade.

Caminhando do processo de exposição para o de busca de informação, percebemos pelos depoimentos prestados, que esta se faz de maneira informal. De acordo com Aguilar (1967), na busca informal, o indivíduo procura ativamente informação para aprofundar 0 conhecimento e 0 entendimento sobre um assunto específico. Esta busca envolve esforços não estruturados e relativamente limitados. 0 objetivo é reunir informação para elaborar um assunto para determinar a necessidade de atuação no ambiente organizacional. Se a necessidade por uma decisão ou resposta é percebida, o indivíduo dedica mais tempo e recursos para a busca.

Entretanto, embasados por Sapiro (1993), para quem a iniciativa de simplesmente coletar e disseminar informação pela empresa não é suficiente para que a mesma maximize o seu potencial e obtenha vantagem competitiva uma vez que esta iniciativa não garante um uso eficiente das informações disponibilizadas, podemos concluir que os gesto res entrevistados, apesar de constantemente coletarem informações sobre 0 ambiente externo, estes ainda não o fazem tendo em mente o conceito mais abrangente de monitoração ambiental.

De acordo com Choo (1998b) reforçado por Barbosa (2002), monitoração ambiental significa analisar informações sobre cada setor do ambiente externo que possa ajudar a alta administração a planejar o futuro da organização, e isso inclui não somente concorrentes, mas, também, fornecedores, clientes, condições e tendências tecnológicas, econômicas, políticas, regulatórias, demográficas e sociais.

No caso dos gestores entrevistados, é interessante perceber que, em suas atividades diárias, o que, em sua grande maioria, os leva a gastar mais tempo é a procura de informações que diferem em função dos cargos e funções que desempenham nas organizações, o que reforça o conceito de Choo (1998c), o autor ressalta que as organizações, ao tentarem compreender 0 ambiente na qual estão inseridas através das informações captadas, estão sujeitas à individualidade inerente às suas crenças $e$ ações, as quais baseiam a sua própria interpretação. $\mathrm{E}$ essa especificidade influencia seu processo de construção de sentido acerca do ambiente e, conseqüentemente, as ações decorrentes deste processo.

De acordo com os resultados das entrevistas foinos possível perceber que as necessidades e 0 comportamento variam de indivíduo para indivíduo e de organização para organização, mas, em sua maioria, o uso da informação está ligado à tomada de decisões estratégicas nas organizações.

Por estarmos analisando um mercado altamente inovador e recente, as maiores dificuldades encontradas pelos entrevistados para obter as informações necessárias estão diretamente relacionadas ao custo para a aquisição de informações especializadas, fontes precisas para a busca das informações, inexistência de tais fontes ou fornecimento de dados incompletos.

Entendendo que o processo de aquisição de informações não possa ser realizado de forma dispersa e de acordo somente com os interesses de cada usuário e sim como uma atividade que requer contínua programação, coordenação e avaliação, percebe-se, nas entrevistas realizadas, a total falta de estruturação, por parte das empresas pesquisadas, no que tange ao alinhamento do comportamento de busca e uso da informação por parte de seus gestores, uma vez que o planejamento dos processos de coleta de informações deveria começar com o desenho do portifólio das principais fontes de informação utilizadas em uma instituição.

De acordo com Choo (1998c), as fontes de informação devem ser monito radas continuadamente 
para que uma organização não fique desatualizada ou perca ocasionalmente informações tidas como relevantes.

Constatou-se, ainda, que, para todos os entrevistados, é fato que as organizações devem diariamente interagir com o ambiente externo a fim de desenvolver e manter sua competitividade e que 0 processo de busca e uso das informações coletadas é de suma importância, sendo considerado por alguns como sendo, mesmo, de máxima importância. Entretanto percebemos que nas empresas de micro e pequeno portes, apesar de seus gestores reconhecerem a necessidade de monitorar o ambiente externo de negócios de forma organizada e sistematizada a fim de garantirem a sua sobrevivência, sua competitividade e seus potenciais de inovação constante, ainda não é uma realidade presente, nestas, a implementação de um processo estruturado de monitoração ambiental.

E, por fim, focalizando um aspecto não menos importante que os anteriores, procedemos à utilização da técnica de incidente crítico com o objetivo de complementarmosa nossa avaliação acerca do estudo do comportamento de busca e uso de informações por parte dos gestores do setor de biotecnologia, à luz do nosso referencial teórico, a partir da explanação de uma situação extremamente relevante para a organização, enfrentada nos 2 últimos anos e a forma como eles procederam para buscar uma possível solução.

De acordo com Choo (2003), a busca da informação é o processo humano e social por meio do qual a informação se torna útil. o processo de busca da informação ocorre em três estágios, a saber: 0 reconhecimento das necessidades de informação, a busca propriamente dita, e, por fim, o uso da informação.

Mediante os resultados obtidos, foi-nos possível observar que o comportamento de busca dos gestores pesquisados pode ser considerado como sendo influenciado por fatores cognitivos, afetivos e situacionais, sendo que as variações nestas dimensões se modificam de acordo com cenários, contexto e pessoas envolvidas, e, certamente, serão estas variações que irão configurar o comportamento de busca da informação.

Ao analisarmos o comportamento de busca dos entrevistados, um ponto em comum cabe destacar: a maioria destes se viram compelidos à busca de informações sobre o ambiente externo de negócios para subsidiar uma possível tomada de decisões frente a uma situação extremamente relevante. Somente em um dos casos pesquisados, a informação já adquirida anteriormente foi considerada como sendo suficiente para que o gestor se sentisse seguro e confiante em sua decisão.

Q uanto à relevância das informações coletadas para uma possível solução às situações principais apresentadas, os casos variaram de acordo com os contextos: para as organizações que não possuem um setor específico de coleta, tratamento e disseminação, as informações adquiridas não foram consideradas como sendo suficientes para reduzir suas incertezas e preocupações.

Um destaque importante: a única organização que declarou não buscar informações externas, foi a terceira empresa - G ESTO R 3 - que após vivenciar uma situação extremamente relevante e desastrosa, mesmo que embrionariamente, implantou um setor específico de $\mathrm{TI}$, direcionado para monitoramento do ambiente externo de negócios, o qual de acordo com o entrevistado, ocasionou, após a sua criação, a reversão da situação crítica, culminando em novas situações extremamente favoráveis.

O utro destaque importante: mesmo a organização que possui maior tempo de mercado, cujo gestor é o mais velho e com maior grau de escolaridade, a que se encontra mais estruturada, que mostrou possuir maior segurança e também garantiu que sua organização trabalha focada em decisões baseadas em informações, também este alegou que, apesar do alto índice de informações obtidas, ainda assim nem sempre estas reduzem suas incertezas.

A partir dessas análises, podemos concluir que o comportamento de busca de informações dos gesto res entrevistados não apresenta uma homogeneidade, não está ligado ao fator idade, ou à escolaridade, ao tempo de maturidade da organização, à estruturação funcional, mas se concentra no indivíduo. Sendo esta, portanto uma atividade social, por meio da qual a informação irá se tornar útil para um indivíduo ou para um grupo.

Assim, o resultado do uso da informação será uma mudança no estado de conhecimento do indivíduo ou de sua capacidade de agir. 
Embasados em Choo (2003), podemos concluir que 0 uso da informação envolve a seleção e 0 processamento da informação, de modo a responder uma pergunta, resolver um problema, tomar uma decisão, negociar uma posição ou entender uma situação. Indivíduos, contextos e necessidades diferentes levam a comportamentos distintos, cujo resultado de ação, uso da informação está ligado ao indivíduo.

Ao procedermos a uma análise da finalidade de uso das informações coletadas sobre o ambiente externo, foi-nos possível perceber, através dos depoimentos prestados, a relação intrínseca entre necessidades x busca xuso de informações.

0 modelo de Choo (2003, p.111-112), segundo suas palavras,

\begin{abstract}
mostra que os ciclos de busca e uso da informação estão inseridos num ambiente de processamento da informação constituído das estruturas cognitivas e disposições emocionais do indivíduo, e de um ambiente mais amplo de uso da informação, determinado pelas condições do meio profissional ou social em que a informação é usada.
\end{abstract}

\section{CO NCLUSÃO}

Após verificarmos que a maior parte dos estudos existentes e de relatos de casos relacionados à monitoração ambiental tratam de ambientes empresariais de grande porte, e entendendo a importância das empresas de micro e pequeno portes para o país, tanto no que se refere à sua constituição quanto à sua importância econômica e às dificuldades que estas passam para se manterem no mercado num contexto em que a incerteza é uma realidade cotidiana, avaliamos que o nosso foco de estudo relacionado às empresas de micro e pequeno portes ligadas ao setor de biotecnologia, setor este extremamente promissor e inovador, mostrou-se bastante pertinente e coerente com os propósitos e objetivos da Escola de Ciência da Informação da Universidade Federal de Minas G erais.

De um modo geral, as atividades de monitoração ambiental são descritas e discutidas a partir de modelos apresentados na literatura, os quais têm como crença que o ambiente externo de negócios deve ser acompanhado sistematicamente, uma vez que os eventos advindos dele determinam o comportamento das empresas. Assim, as organizações podem ser consideradas tanto como receptoras de sinais advindos do ambiente externo quanto, ao mesmo tempo, transmissoras de sinais ao ambiente, sendo que elas detectam ou recebem tais sugestões e usam a informação para se adaptar às novas condições. Então, tipicamente, obter recursos significa, para as organizações interagir com as entidades que as controlam. Nesse sentido, as organizações dependem de seus ambientes e a sobrevivência é parcialmente explicada pela habilidade em enfrentar as contingências a mbientais.

Ao enfrentar um contexto em que o grau de incerteza é cada vez mais elevado, as organizações consideram que não há espaço para erros, e reconhecem uma necessidade cada vez maior de um gerenciamento efetivo das informações referentes ao mercado em que atuam. É nesse cenário que a monitoração ambiental tem se apresentado como ferramenta indispensável à própria sobrevivência da organização.

Subjacente aos estudos voltados para a gestão da informação, de um modo geral, e para a monitoração ambiental em particular, encontra-se a idéia básica de que a informação é o fator-chave para que as pessoas conheçam e "criem" o conhecimento propulsor da competitividade organizacional. No entanto, levantar as necessidades info rmacionais não é tarefa fácil, pois lidamos com pessoas e seus diferentes comportamentos cognitivos frente à informação e ao uso da mesma como fator de vantagem competitiva.

O $s$ dados obtidos através das entrevistas realizadas com gestores das MPEs do setor de biotecnologia mostraram que a permanência de suas organizações no ambiente de negócios não possui relação direta com a existência de atividades profissionais ou com infra-estrutura especializada para 0 trato da informação.

A despeito de não utilizarem mecanismos formais ou sistemáticos de obtenção, processamento e análise de informação, os gestores têm consciência de que precisam estar informados a respeito de suas empresas e do meio em que atuam.

Através dos depoimentos prestados, ficou claro que os gestores pesquisados, em sua maioria, compreendem a importância de monitorar 0 ambiente externo de negócios, assim como ficou claro, que é 
fato que as organizações devem interagir diariamente com o ambiente externo para desenvolver e manter sua competitividade e que o processo de busca e uso das informações coletadas é de suma importância, sendo considerado por alguns como sendo, mesmo, de máxima importância.

Entretanto percebemos que, nas empresas de micro e pequeno portes, apesar de seus gestores reconhecerem a necessidade de monitorar 0 ambiente externo de negócios, estes, em sua maioria, consideram que não têm problemas de acesso a informações que Ihe sejam necessárias para o gerenciamento de suas empresas e para compreenderem o que ocorre no mercado. Assim, do lugar que ocupam, os gestores acreditam que sabem tudo a respeito de seus respectivos negócios e que não precisam sistematizar atividades de gestão da informação ou de monitoração ambiental em suas empresas. Essas conclusões mostram que as atividades relacionadas à prática de monitoração ambiental, nas empresas de micro porte, são em sua maioria informais, inexistindo uma equipe capacitada responsável por elas, ou infra-estrutura para que sejam sistematizadas. E, nas empresas de pequeno porte, há, ainda que embrionariamente, uma mudança de postura e de conduta.

Assim, entendemos que o comportamento de busca e uso da informação não é uno e deve englobar a to talidade da experiência humana: os pensamentos, os sentimentos, as ações e o ambiente onde estes se manifestam. Confirmando C hoo (2003), o usuário da informação é uma pessoa cognitiva e perceptiva; a busca e o uso da informação constituem um processo dinâmico, que se estende no tempo e no espaço; 0 contexto em que a informação é usada determina de que maneiras e em que medida ela é útil.

Q uanto ao impacto das informações coletadas para uma possível solução às situações relevantes apresentadas, os casos variaram de acordo com os contextos: para as organizações que não possuem um setor específico de coleta, tratamento e disseminação, as informações adquiridas não foram consideradas como sendo suficientes para reduzir suas incertezas e preocupações.

$\mathrm{Q}$ uanto às empresas de pequeno porte, a redução de suas incertezas mediante a coleta de informações se mostrou bastante diversificada, embora todos os gestores alegassem possuir um setor específico para coleta, tratamento e disseminação, mesmo que pela área de marketing.

Assim, consolidando o modelo de busca e uso da informação de Choo (2000), podemos afirmar que são as dimensões cognitiva, afetiva e situacional somadas que irão se constituir como comportamento de busca e uso, e em que medida esta busca e este uso contribuem para a redução das incertezas, ou não.

Tal como as pessoas, fatores como a idade, a função, a rotina de trabalho mostraram-se, também, através das entrevistas, como fortes indicado res de como os gestores atuam no ambiente de negócios, quais são os seus focos de atenção, as suas prio ridades no que se refere à resolução de problemas e à redução de suas incertezas, bem como quais são as relações e as interações que possuem, que estão pré-dispostos a estabelecer e como mantêm e criam novas interações no meio de negócios.

O s resultados levam-nos a concluir que ambientes, cenários e pessoas diferentes têm necessidades, comportamentos, análises e usos de informações diferenciados. Não existe um padrão único de comportamento de busca e uso de informações externas, e a redução das incertezas independe da quantidade de informação coletada e ou mesmo processos estruturados. A redução da incerteza se concentra nos indivíduos e na sua capacidade pessoal de adicionar valor à "informação", informação esta que poderá ser utilizada para responder a uma pergunta, resolver um problema, tomar uma decisão, negociar uma posição ou compreender uma situação.

\section{REFERÊN CIAS}

AG UILAR, F.J. Scanning the business environment. New York: Macnillan, 1967.

BARBO SA, R.R. Acesso e necessidade de informação de profissionais brasileiros: um estudo exploratório. Perspectiva em Ciência da Informação, Belo Horizonte, v.2, n.1, p.5-35, 2002.
CHOO, C.W. Information management for the intelligent organization: the art of scanning the environment. 2.ed. [S.I.] : ASIS, 1998a. (ASIS monograph series).

CHOO, C.W. Information management, knowledge management, and the information professional In: $\mathrm{CHO}$, C.W. 
Information managementfor the inteligent organization. 1998b. Cap.9, p.257-278.

CHO O, C.W. Web work: Information seeking and knowledge work on the world Wide Web. Dordrecht Kluwer, 2000.

CHO O, C.W. The knowing organization: how organizations use information to constructmeaning, create knowledge and make decisions. 0 xford University Press, 1998c.

CHO O , C.W. A organização do conhecimento: como as organizações usam a informação para criar significado, construir conhecimento e tomar decisões. São Paulo: Senac, 2003.

CULNAN, M.J. The Dimensions of perceived acessibility to information: implications or the delivery of information systems and services. Journal of the American Society for Information Science, v.36, n.5, p.302-308, 1985.

DAVEN PO RT, T.; PRUSAK, L. Conhecimento empresarial: como as organizações gerenciam o seu capital intelectual. Rio de Janeiro: Campus, 1998. 237p.

DERVIN, B. From the mind's eye of the "user": the sense-making qualitative-quantitative methodology". In: G LAZIER, J.D.; PO WELL, R.R. (orgs.). Q ualitative research in information Management. Englewood: Libraries Unlimited, 1992.

DILL, W.R. The impact of environment on organizational development. In: Concepts and issues in administrative behavior. Englewood Cliffs, NJ: Prentice-Hall, 1962.

EISENBERG, M.; SCHAMBER, L. Relevance: the search for a definiton. In: ASIS AN N UAL MEETIN G HELD IN MEDFO RD 51. Medford, 1998. Proceedings of. Learned Information, 1998. p.162-168.

G ERSTBERG ER, P.G .; ALLEN, T.J. C riteria used by research and development engineers in the selection of an information source. Journal of Applied Psychology, v.52, n.4, 272-279, 1968.
IN STITUTO MCKINSEY. Produtividade no Brasil: a chave do desenvolvimento acelerado. Rio de Janeiro: Campus, 1999.

KUHLTHAU, C.C. Seeking meaning: a process approach to library and information services. Norwood: Ablex, 1993.

MCGEE, J.; PRUSAK, L. G erenciamento estratégico da informação: aumente a competitividade e a eficiência de sua empresa utilizando a informação como uma ferramenta estratégica. Rio de Janeiro: Campus, 1994.

PAIM, I.; NEHMY, R.M.; G UIMARÃES, C. Problematização do conceito de "qualidade" da informação. Perspectiva em Ciência da Informação, v.1, n.1, p.111-119, 1996.

PO RTER, M.E. Estratégia competitiva: técnicas para análise de indústrias e da concorrência. 7.ed. Rio de Janeiro: Campus, 1997. $362 p$.

RO USE, W.B.; RO USE, S.H. Human information seeking and design of information systems. Information Processing and Management, v.20, v.1-2, p.129-138, 1984

SAPIRO , A. A inteligência empresarial: a revolução da ação competitiva. Revista de Administração de Empresas, v.33, n.3, p.106-124, 1993.

SARACEVIC, T. Relevance: a review of and a framework for the thinking on the notion in information science. Journal of the American Society for Information Science, v.26, n.6, p.321-343, 1975.

TAYLO R, R.S. Value-added processes in information systems. Norwood: Ablex, 1986.

WILSO N, T.D. O nu ser studies and information needs. J ournal of Documentation, v.37, n.1, p.3-15, 1981.

ZMUD, R.W. An empirical investigation of the dimensionality of the concept of information. Decision Sciences, v. 9, n.2, p, 187$195,1978$. 